\title{
Africanidades, corporeidade e opacidade nos primórdios da história da imprensa ilustrada
}

\section{Africanities, corporeity and opacity in the early days of the illustrated press history}

Túlio Henrique Pereira ${ }^{1}$

\begin{abstract}
RESUMO
Este artigo se propõe a analisar parte específica da produção da imprensa ilustrada na Bahia, especialmente do jornal A Coisa (1897-1904), o caráter de seus textos com temáticas africana $\mathrm{e}$ afro-brasileira, pensando a autoria organizada por grupos de redatores amigos com propósitos ideológicos consonantes à segmentação impulsionada por países como a França e os Estados Unidos. Ao perceber a efetiva atuação de Arthur Arezio da Fonseca, redator e caricaturista negro, assim como a presença de nomes e estereotipia produzidos por e sobre africanos e seus descendentes, interessei-me por analisar como a temática das africanidades e da corporeidade étnica se deu de forma comprometida e distanciada, de modo a contribuir para a opacidade ou visibilidade de determinados padrões na imprensa ilustrada produzida na Bahia.
\end{abstract}

Palavras-chave: História da Imprensa, Imprensa Ilustrada; Africanidades, Corporeidade, Arthur Arezio da Fonseca.

\begin{abstract}
This article propose is to analyze a specific part of the illustrated press production in Bahia, specifically the newspaper A Coisa (1897-1904), its texts with African and Afro-Brazilian themes, taking in consideration the authorship organized by copywriters' friends' groups with ideological purposes in line with the segmentation driven by countries like France and the United States. When I perceive the effective performance of Arthur Arezio da Fonseca, a black man who was a writer and a caricaturist, as well as the presence of names and stereotypy produced by and about Africans and their descendants, I develop the interest in analyzing how the theme of Africanities and ethnic corporeality took shape compromised and distanced, in order to contribute to the opacity or visibility of certain patterns in the illustrated press produced in Bahia.
\end{abstract}

Keywords: History of the Press, Illustrated Press; Africanities, Corporeity, Arthur Arezio da Fonseca.

\footnotetext{
${ }^{1}$ Doutor em História Social pela Universidade Federal de Uberlândia (UFU). Estágio PósDoutoral no Programa de Pós-Graduação em História do Brasil da Universidade Federal do Piauí (UFPI). Bolsista PNPD/CAPES. Teresina - PI - Brasil. E-mail: tuliohenriquepereira@gmail.com.
} 


\section{A Coisa num lugar da história da imprensa}

Ilm. Sr. J. Borreaux - Muito me penhorareis com a publicação das seguintes linhas:

Li na vossa Coisa do numero passado uns tópicos referentes aos africanos residentes aqui, onde taxados de vis, sumiticos, usurários, e ocorreu-me perguntar ao seu autor em que escola foram elles educados?

$\mathrm{Na}$ escola dos brancos. Foram os seus ex-senhores que assim os preparam.

Na senzala recebiam periodicamente parca ração de carne podre e farinha mofada.

Sahiam ao ganho com taboleiros prenhes de verdura e se vendiam pelo mínimo preço estipulado pelo senhorio, ou se regressavam trazendo restos da mercadoria eram aferrolhados no tronco ou cantavam a gloria na "casca da vacca".

Foi entoxicando o estomago com os alimentos anti-hygienicos que $\underline{\mathrm{o}}$ senhor lhes infligia que elles aprenderam a comer "carurús de cincoenta dias".

Foi pela aritméthica do senhor que lhes não perdoava um réis, que elles aprenderam a ser avarentos.

Conquistada a sua liberdade a custa da economia que iam fazendo de vinténs que ganhavam particularmente, às escondidas do senhor, elles que já estavam acostumados ás mas comidas, não procuraram melhorar á sua alimentação.

O africano na febre da liberdade, delirava com o dinheiro.

Baldo de intelligencia, sem outro conselheiro que não fosse sua própria ignorância, accumular dinheiro e mais dinheiro foi sempre a sua maior aspiração.

E é o que se tem visto.

Não se os crimine, pois. Criminem aos seus senhores que eram brancos e se diziam civilisados e não souberam educa-los para a vida social.

Dizem que João de Mattinhos deitava o toucinho no fumeiro para que sua panella aspirasse-lhe somente o cheiro.

Este não era africano.

Bahia, 24 de fevereiro de 1898. 
De vosso criado e obrigado - Ojou. ${ }^{2}$

Na edição d'A Coisa do dia 6 de março de 1898 - semanário ilustrado e satírico, lançado em 30 de agosto de 1897 com duração até outubro de 1904, há o aparecimento de uma personagem do sexo masculino que assina suas participações no periódico com o nome Ojou. Não é a primeira evidência de Ojou nas páginas deste jornal cujo propósito editorial se volta à sátira política e aos temas do cotidiano tratados com humor e chiste.

O periódico cujas dimensões variam de $12 \times 16,5 \mathrm{~cm}$ até 22,5 × $32 \mathrm{~cm}$ é compreendido como uma publicação segmentada pela imprensa ilustrada inaugurada na Europa, cujos exemplos de sucesso em número de tiragem, qualidade de ilustrações e alcance foram reconhecidos no Brasil pelos produtores dos impressos da época de produção e circulação d'A Coisa, como também utilizados com o propósito de aproximação da segmentação de um estilo. Percebo A Coisa, todavia, não como reflexo do que se produzia no mercado dos periódicos ilustrados na Europa e América do Norte ou até mesmo no Rio de Janeiro, ${ }^{3}$ mas sim como a possibilidade de criação de imagens e da inserção de um marco histórico e de narrativas das agendas políticas e socioculturais regionais e nacionais da Bahia e do Brasil. O impresso conseguiu ter vida útil e regularidade maiores que seus contemporâneos e foi o responsável pela organização de um grupo de amigos com o mesmo ideal por longos anos.

\footnotetext{
2 Optou-se por trazer a forma escrita da época. Desse modo foram respeitados os usos formais da escrita utilizada pelos redatores do impresso $A$ Coisa, sua pontuação, e a grafia das palavras daquele contexto. Para mais, ver: A Coisa, 6 mar. 1898, ano I, n. 28.

${ }_{3}$ As gravuras reconhecidas pelos estudiosos das imagens como sendo um repertório autêntico correspondem àquelas imagens xilográficas, litográficas e clichês fluminenses assinados por nomes famosos no Brasil na década de 1880, como Angelo Agostini, Pereira Neto, Vale e Pedro Américo. Essas pinturas, repertório dos impressos ilustrados como A Semana Illustrada, Revista Illustrada, Vida Fluminense, Rio $\mathrm{Nu}$ e $A$ Maçã foram publicadas no Rio de Janeiro e provocaram a segmentação e a generalização da caricatura produzida no Brasil.
} 
Embora A Coisa possua formato aos moldes de seus contemporâneos no exterior Le Petit Journal: Supplément Illustrét e The Verdict ${ }^{5}$, isto não descaracteriza o seu valor estético e histórico a demarcar um modo de fazer, ver, criar e representar personagens célebres e anônimas de uma Bahia e de um Brasil em processo de consolidação política e identitária. Ainda em se tratando da Bahia, A Coisa é contemporânea do impresso ilustrado A Malagueta (1897-1898), organizado por parte do mesmo grupo editorial e antecedido pelo projeto gráfico ilustrado O Faisca (18851887).

O imprenso A Coisa teve vida regular de seis anos, 1897, 1898, 1899, 1900, 1901 e 1904, não compreendendo o hiato de três anos e quatro meses, a considerar a interrupção de suas publicações entre junho de 1901, perpassando todo o ano de 1902 e 1903 até agosto de 1904. Embora a revista se tratasse de um hebdomadário, publicação semanal, observou-se nas suas páginas que não havia uma regularidade ou data fixa para que a edição fosse lançada, e em alguns meses ficou constatado mais de uma edição por semana. A escolha desse periódico enquanto objeto de análise se dá por sua durabilidade, regularidade e relevância dada ao seu conteúdo

\footnotetext{
${ }^{4}$ Fundado em Paris em 1863 pelo empresário e jornalista Moïse Polydore Millaud (1813-1871), teve duração até o ano de 1944. As gravuras eram produzidas especialmente pelo francês de família inglesa Fortuné-Louis Méaulle (1844-1901). O jornal possuía a regularidade de oito páginas, sua linha editorial versa sobre artigos de opinião, reclames sensacionalistas, fatos políticos, folhetins e estampas na capa e na contracapa. O suplemento ilustrativo passou a ser novidade editada às sextas-feiras, as imagens tomaram protagonismo a partir de 1884, quando o jornal aumentou o número de associados e de exemplares vendidos, tornando-se relevante para a sociedade francesa da época.

${ }^{5}$ The Verdict também grafado apenas como Verdict é um impresso semanal ilustrado, humorístico e político criado na cidade de Nova Iorque pelo empresário, banqueiro e aspirante a político Oliver Hazard Perry Belmont (1858-1908), as inicias O. H. P. Belmont aparecem no canto superior direito da página da revista seguida por sua função de presidente do impresso. No canto superior esquerdo observa-se o nome do editor Alfred Henry Lewis (185*-1914), não há consenso quanto a data de nascimento de Lwis, existem atribuições do seu nascimento em 1855, mas também em 1857 e 1858. Embora não apareça a assinatura do artista plástico e cartunista George Benjamin Luks (1867-1933) este assina várias ilustrações em cartoon publicadas na revista. Também colaborou com gravuras para The Verdict, Horace Taylor (1881-1934). Para mais ver: (APPLEGATE, 2008; GAMBONE, 2009; DEARMENT, 2013).
} 
visual peculiar, e também por tratar da inserção de personagens negras seja a partir da estereotipia ou da participação dos seus produtores, em especial o gravurista e redator Arthur Arezio da Fonseca.

O periódico foi gerenciado por K. Brito e teve a colaboração dos redatores Dois Bemões, Jayme Borreaux, Bombardino e Zéca Gaude. Grande parte de suas gravuras é produzida pela técnica da xilogravura (LEHMKUHL; PEREIRA, 2016, p. 283). Todavia, não utilizo imagens visuais enquanto objeto de análise neste texto, mas sim a emergência de uma carta atribuída a uma personagem africana, cuja participação no impresso se dá em vários momentos da sua circulação. A carta e os telegramas de Ojou e de outros redatores e leitores constroem imagens abstratas do corpo e de identidades formuladas ou atribuídas por/aos africanos e afro-brasileiras.

A partir destas linhas introdutórias reitero que o interesse é o de analisar os sentidos visuais presentes no jornal $A$ Coisa, o caráter genérico de suas imagens construídas a partir de textos com temática africana e afro-brasileira, especificamente do surgimento da personagem Ojou. A análise se deu por meio da leitura e observação desses textos a forjarem a representação do cotidiano. A percepção da emergência de discursos históricos com conteúdo étnico-racial permitiu a visualização de determinados tipos e identidades em ação no meio social baiano. Resta saber que as características e as implicações sociopolíticas e culturais dos estudos étnico-raciais, da história cultural e das africanidades norteiam e amparam a escrita desse ensaio, voltado às consonâncias ideológicas estritas às personagens negras.

\section{Arthur Arezio da Fonseca: intelectualidades negras}

São atribuídas ao tipógrafo, redator e gravurista baiano Arthur Arezio da Fonseca (1873-1940) grande parte das imagens inseridas no periódico A Coisa, assim como textos e direção tipográfica. Luis Guilherme Pontes Tavares, aponta Arthur 
Arezio como um dos precursores dos estudos das artes gráficas no Brasil, especialmente na Bahia, mesmo embora não tenha recebido o reconhecimento em vida ou na posteridade. Foram encontrados apenas dois estudos sobre o legado do artista, sendo um do professor Luis Guilherme Pontes e a pesquisa da professora Angeluccia Habert, a tratarem sobre a obra e a biografia de Arezio.

O gravurista Arthur Arezio foi responsável também pelo estudo dos termos gráficos e editou o livro Diccionário de termos graphicos (1936) e Serões tipographicos (1905). Serões tipographicos é um livro com trinta páginas, no qual as influências europeias do gravurista e tipógrafo são indicadas. A percepção da influência recebida por ele dos estudos sobre a tipografia e a gravura pode ser evidenciada na passagem que o autor faz em um de seus livros, uma espécie de advertência aos leitores de que "a pessoa que pretender aprender a arte tipographica deve saber ler e escrever bem, ter noções de frances, de desenho e de mathematicas" (sic) (FONSECA, 1909 , p. 38).

Arthur Arezio da Fonseca é indicado enquanto homem negro, que, no entanto, não elaborou representações múltiplas em imagens visuais de homens e mulheres negros tal como o fez com as imagens múltiplas de homens e mulheres brancos representados em gravuras xilográficas n'A Coisa. De todas as edições analisadas, apenas seis representações visuais de mulheres negras foram observadas no imprenso, incluindo uma imagem que não é atribuída a ele.

As considerações acerca da sua negritude vieram a lume pelo seu principal estudioso, o professor Luis Guilherme Pontes Tavares. Em entrevista, publicada e analisada em sua tese de doutoramento, realizada com o neto de Arezio, Oldemar Victor dos Santos, Tavares aponta que o neto Oldemar dizia que o seu avô Arezio "se referia aos negros em geral como 'a corporação', da qual ele não era membro' (TAVARES, 1995, p. 17). Guilherme Tavares dedica uma página da sua pesquisa para justificar o fato de não ter se debruçado sobre o tema da negritude de Arthur Arezio, 
e sinaliza sua justificativa com o subitem "nem tanto pardo, nem tampouco seabrista" (TAVARES, 1995, p. 17). O autor temia desenvolver um relato caricatural do gravurista, enfatizando que o próprio Arezio tratou em vida de "afastar de si a identidade com a sua descendência africana" (TAVARES, 1995, p. 17). Desse modo entendo que a não representação da multiplicidade desses corpos negros n'A Coisa se deu porque, enquanto um homem negro do seu tempo, e inserido no lugar de prestígio da sociedade baiana, Arthur Arezio se via um corpo sem referências positivas, e desse modo, se apresentava impelido a reproduzir o discurso do racismo introjetado que o fazia opacizar as representações positivas dos negros do seu cotidiano, eclipsadas pela cegueira que o impedia de enxergar a sua própria identidade e valor. ${ }^{6}$

Conforme observado em Nilma Lino Gomes esse processo de rejeição ou de não identificação de si que acomete o negro que se opõe ao próprio negro, aquele que deveria ser o seu espelho, se deve porque há um "processo conflitivo [...] construído socialmente, vivido e aprendido no grupo, na família" (GOMES, 2006, p. 140). E, ainda que o negro pertença a uma família consciente de sua identidade e que essa seja conhecedora dos seus valores, o negro ou a negra encontram nas suas referências externas, em uma sociedade que foi colonizada por europeus, imagens e textos que não refletem os valores assimilados por suas famílias, provocando cisões e confrontos de afirmação e pertencimento social, "esse movimento revela que, tanto a aceitação do ser negro quanto a sua rejeição não se dão apenas na esfera da racionalidade [...], tal como as relações raciais aqui se realizam, a expressão desse conflito passa, necessariamente, pelo corpo" (GOMES, 2006, p. 140).

\footnotetext{
${ }^{6}$ Para mais informações acerca do processo de introjeção do racismo, negação do negro pelo próprio negro, e do condicionamento psicológico a impedir o reconhecimento do negro da sua própria identidade enquanto cidadão negro, ver as seguintes obras: (GOMES, 2006; BASTIDE, 1983; DOLTO, 2012).
} 
Ignorar a cor, rejeitá-la ou ser indiferente a ela, é conforme nos fala Frantz Fanon, um modo de aceitar ou dar suporte a uma cor específica tomada enquanto cor legítima: o branco. Consideramos com o auxílio de Fanon que o racismo foi arquitetado nas sociedades colonizadas de forma que há uma construção sistematizada para se perceber o negro, e esses são doutrinados a verem o mundo a partir da linguagem, da memória coletiva, do consciente e do inconsciente coletivo, e das imagens produzidas pelos colonizadores brancos, que determinaram o que deveria ser desprezado ou superestimado.

Lewis R. Gordon no prefácio do livro de Fanon faz com que saltemos os olhos para algumas questões bastante contundentes sobre a condição do aprisionamento do corpo e da mente negros num mundo pós-colonial: primeiro elucida a questão da liberdade em duas vertentes, "a liberdade requer visibilidade, mas, para que isto aconteça, faz-se necessário um mundo de outros [...] a liberdade requer um mundo de outros. Mas o que acontece quando os outros não nos oferecem reconhecimento?", e em seguida, fala sobre a opacização e o forjamento de um devir sobre o negro: “espera-se que os negros não tenham sido negros a fim de legitimarem-se como negros, o que é uma tarefa impossível", e continua, "os negros [...] enfrentam o problema da sua relação com a razão e com o Eu enquanto indígenas do mundo moderno" (itálico do autor GORDON, 2008, p. 16 e 17), todavia o Eu não pode ser o que ou quem são, e concluo que, o Eu também não encontra suporte para ser o que quiser; ao menos no contexto de instabilidade experienciado por Arthur Arezio e por tantos homens e mulheres negros de um Brasil desconstruído, embora em processo de construção da sua ideia de nação e valores. Desse modo entendo que Gordon e Fanon exercitam sua alteridade ao tomarem a concepção de mundo enquanto representação cunhada por Arthur Schopenhauer, invertendo suas concepções de Eu e do Outro. Na formulação fanoneana do pós-colonialismo, o Outro são os europeus/brancos, e o Eu os povos da diáspora/negros. 


\section{Na febre da liberdade: a Bahia de Ojou na imprensa ilustrada}

Ao voltar o olhar para a citação do início, aquela assinada pela personagem Ojou da edição de 6 de março de 1898, percebe-se que a autoria é reavivada enquanto resistência negra à jocosidade explicitada no editorial assinado por Jayme Borreaux. Neste número Ojou escreveu uma carta de ortografia regular e formal para a época, em resposta ao editorial atribuído ao redator Borreaux.

Em 27 de fevereiro de 1898, o editor-chefe d'A Coisa, Jayme Borreaux publicou editorial sobre o Carnaval de Salvador, criticando a presença ou a tomada das ruas pelos grupos de etnias africanas no período festivo da capital. $\mathrm{O}$ autor sugere certo repúdio ao protagonismo do povo negro que toma frente nos desfiles de rua:

Esteve assim, assim o carnaval de 98; os "Africanos" é que deram bem alto a sua nota, transformando esta cidade durante os três dias de folia numa verdadeira colônia africana.

Tomaram parte este anno nas festas carnavalescas, além de outros, os seguintes clubs:

PANDEGOS DA AFRICA

Que se póde dizer dos Pandegos!

Saíram na pura ponta, na pontíssima!

Castigando a cara sedaria coberta de ouro, arrastando as creoulas apaixonadas, que muito lhes ajudaram a entoar o canto de Emanjá (Mãi d' agua); “Aoderecê é qui émanjá, potábelèbê aôuai torotim blá choreuê".

Conquistaram o logar de honra.

EMBAIXADA AFRICANA

Desde a sua creação, que data tres ou quatro annos, que tem dado grande realce ao carnaval, colhendo sempre innumeras ovações.

Apresentou-se ao publico no domingo e terça-feira passado esplendidamente, com sua cavalaria de caçadores de Quioco, com o seu rei d'Abomey (sic) e suas Bacamas, com seu rochunchudo Muzumbo-Tembo e seus todos exquissitos personagens, cheios de miçangas e burundangas.

Mas, o que realmente nos embasbacou diante de toda, aquela miscelania de vestimentas, foi haver a Colonia Africana residente aqui preparado uniforme especial para receber a Embaixada. 
Si nol-o não dissesse a própria Embaixada, não acreditariamos, sériamente.

Esta colonia vil, sumitica, avarenta?

Esta colonia cujos representantes preferem morrer devorados pelas chammas incandescentes do incêndio a não deixarem o sacco do dinheiro accumulado durante muitos dias de fome?

Esta colonia de usurarios que comem caruru de cincoenta dias e sempre queixando-se de- "disgeston"?

Os trajes de gala que conhecemos destes filhos do chamico continente é o que elles envergam quando vão á missa ou ao enterro do "quarente": o casaco sebento que o doutor despresou, a cartola enferrujada com que o filho do freguez d'agua varria a casa, a roupa velha inutilisada que o dono encostou.

E' de admirar! Só sob pena de perder a cabeça ou por decreto de Ogun, é que achamol-a com coragem de reformar a brochura escangalhada; mas por "patriotismo, por vontade espontanea, por amor ao seu soberano, não! .

Foi um verdadeiro milagre que operou neste ponto a Embaixada.

Ou foi a Embaixada a offertante? [...]

FILHOS D'AFRICA

Apresentaram-se engraçados, com seu estandarte bordado de busios.

Entre outras cantigas ouvimos-lhes:

"O'gungê arêre ouim parará quejou" "Abeou abébé qui mi sôquêô". CHEGADA AFRICANA

Guarda de honra assim charanga immensa. ${ }^{7}$

Jayme Borreaux em sua observação do desfile cita quatro grupos carnavalescos compostos com descendentes de africanos. Os grupos citados foram: Pandegos da África (alegres, engraçados da África), Embaixada Africana, Filhos d'África e Chegada Africana. Conforme grifo, foram destacadas as palavras que remeteram à etnia ou a cor dos afrodescendentes e aos qualitativos designados a eles. Ao grupo Pandegos da África, o autor trouxe os termos: Creoulas em referência às mulheres negras e mulatas que apesar de descenderem de alguma etnia africana seriam nascidas no território do Brasil, com genealogia miscigenada ou não; Africanos enquanto uma possível tentativa de unificar a pluralidade étnica de descendência

\footnotetext{
${ }^{7}$ A Coisa, 27 de fev. 1898, ano I, n.27. Carnaval. 
negro-africana transplantada ao Brasil e presente na Bahia em multiplicidade; Colônia Africana enquanto uma tentativa de agrupar essas descendências num único segmento estrangeiro e distante do reconhecimento da nacionalidade brasileira oferecido a todos os estrangeiros viventes no Brasil, promulgada pela Constituição Federal de 1891; Tomaram para aludir ao ato de os negros dominarem a festa carnavalesca daquele ano; Saíram na ponta, uma expressão que também remete ao altruísmo dos negros e seu protagonismo na festividade popular ao sair na frente e, finalmente, Conquistaram o seu logar de honra (sic). Acontece, porém, que o Carnaval não era visto naquele tempo como uma festividade honrosa para a sociedade.

Segundo o médico, poeta e historiador do período imperial, o baiano Alexandre José de Melo Morais Filho (1844-1919), o Carnaval é um costume popular recebido como herança da metrópole portuguesa, e teria sua origem mais antiga oriunda do povo judeu (MORAIS FILHO, 2002, p. 115). Para Melo Morais o entrudo, como era conhecido o Carnaval durante o Império e a Primeira República, tomava características muito particulares ao ser apropriado por "selvagens mestiçados". Como homens do seu tempo, Melo Morais, assim como Nina Rodrigues trataram o elemento negro ora como selvagem, criado, vassalo e serviçal.

Suas obras nos servem por trazerem vestígios que auxiliam na montagem de dada realidade de um tempo, as hierarquias, as formas de ver, os preconceitos e a estrutura da época, e também a visualidade do modo como se uniam no cortejo das ruas moças, senhoras, senhorios, rapazes estudantes de medicina, mulatas, crioulas na brincadeira do entrudo. Contudo, a narrativa do seu estudo oferece-nos pistas de que, embora, mulatas e senhoras dançassem o entrudo no cortejo, as hierarquias

\footnotetext{
8 "Os textos da Constituição de 1891 permitiram se levantassem dúvidas na interpretação do seu alcance [...] Objeto de lei constitucional do Império e da República, foi muito criticada [...] isso fêz com que muitos portuguêses, contrários ao novo Estado, a fim de obterem vantagens pessoais, se declarassem a seu favor, e aí se tinha o estrangeiro concorrendo com os naturais do país, em várias ocasiões, como no provimento de cargos e na obtenção de honrarias, e muitas vêzes, em detrimento dos próprios crioulos" (MELO, 1949, p. 20-21).
}

Caderno Pesquisa do Cdhis | Uberlândia, MG | v.32 | n.1 | jan./jun.. 2019 | ISSN 1981-3090 
eram muito bem definidas, dirimindo qualquer interpretação extemporânea de que pudesse existir uma democratização ou ideia de igualdade nos dias do evento, que começava na Bahia, três dias antes do período da quaresma e seguia até a quartafeira de cinzas. O entrudo na Bahia foi, segundo as considerações de Melo Morais, a manifestação menos brutal quando comparada àquelas realizadas nos países estrangeiros, e a esse fato ele considera o "amestiçamento brasileiro" (MORAIS FILHO, 2002, p. 116).

Desse modo, é possível interpretar que desde as primeiras manifestações do entrudo no período da Colônia e do Império no Brasil, o elemento negro esteve presente. E chegando mais tarde, quando da Abolição da escravatura em 1888 e do advento da República, a protagonizar o Carnaval de Rua da Bahia, conforme considerações de Nina Rodrigues e de documentos, tais como os impressos baianos: A Coisa do dia 27 de fevereiro de 1898, 6 de março de 1898, Jornal de Notícias do dia 11 de fevereiro de 1899 e Diário da Bahia do dia 16 de fevereiro de 1899.

Ao grupo Embaixada Africana as palavras e frases em destaque são as seguintes: Ovação para aclamação pública; Exquissitos personagens (sic) em alusão ao reconhecimento positivo de suas caracterizações e fantasias; Cheios de Miçangas e Burundangas reconhecimento da riqueza de seus trajes; Colônia vil alusão ao pouco valor ou ao fato de a "colônia africana" ser composta de membros ordinários sem valor social para a sociedade baiana da época; Sumitica e Avarenta relacionando seus membros a pessoas ordinárias apegadas ao dinheiro, avarentos de natureza; Que comem caruru de cinquenta dias, modo de enfatizar suas avarezas e suas faltas de consciência ou pouca criatividade alimentar, ou pobres financeiramente a ponto de passar fome; Chamico continente, dando a entender que se trata a África de um continente queimado, trigueiro, moreno; Casaco sebento, Cartola enferrujada e Roupa velha inutilisada (sic) para dizer que as roupas que esses homens e mulheres vestiam 
eram lixo desprezado pelos brancos "doutores"; Brochura escangalhada para dizer que não tinha funcionalidade, fracos.

Ao grupo Filhos d'África, Jayme reservou apenas o qualitativo engraçado, e ao grupo Chegada Africana, denominou de banda imensa, possível alusão ao cansaço que rendeu na plateia pela falta de atratividade ou mesmo pela grandiosidade numérica e imponente da banda. Destaca-se também a utilização da língua africana Iorubá, na ilustração dos cânticos carnavalescos entoados pelos grupos. E novamente demonstra o reconhecimento do autor para a distinção das culturas múltiplas advindas de África, ainda que neste editorial não fosse sua intenção demarcá-las, mas sim unificá-los como sendo um único povo constituído por um continente que aos olhos de seu autor parecia mais uma colônia trigueira.

Se, por um lado, o tom jocoso do redator-chefe revelou um forte conteúdo discriminatório em relação aos africanos e seus costumes, por outro, revelou aspectos do cotidiano desses indivíduos, pelo visto bastante difícil e regrado. Pode-se perceber de forma clara, que o carnaval não era apenas divertimento. Constituía-se para a população negra, neste caso, os africanos, um espaço de afirmação culturalpolítico-racial-religiosa, traduzida na forte presença nas ruas, na riqueza das indumentárias dos que desfilavam como também dos que iam recebê-los, nos cânticos de louvor aos orixás; era o candomblé ganhando as ruas. É interessante frisar a surpresa do redator em relação ao uso de trajes pomposos pelos africanos, ao que parece incompatível com o estado de penúria. Aos olhos do redator, era uma demonstração da somiticaria (sic) dos africanos (CUNHA, 2004, p. 233).

O Carnaval era originalmente uma comemoração da elite portuguesa no Brasil, herdeira dos costumes da metrópole. Mas, todavia, o elemento negro parecia fazer parte integrante das manifestações do Entrudo. Na passagem do Império para a República, a elite baiana incomodada e representada pela força institucional da polícia e do Governo, solicitou em vários momentos o fim das comemorações do Entrudo devido ao ascendente protagonismo negro. E na década de 1853 se deu a 
primeira proibição da festa. ${ }^{9}$ Segundo Nina Rodrigues o elemento negro no Brasil tornou o Carnaval uma prática africana, momento no qual os negros podiam exaltar suas crenças, louvar os seus santos e recordar sentimentos íntimos (RODRIGUES, 2008, p. 169). Esse protagonismo ascendente dos grupos negros e o incômodo da elite para com eles podem ser observados numa passagem do livro de Melo Morais, ao descrever sua interpretação pejorativa de um grupo africano chamado Cacumbis. Segundo suas observações "ao anoitecer, os Cacumbis, espécie de mascarada africana, dançavam e cantavam em bárbara passeata, agitando chocalhos, tocando marimbas, batendo com os punhos em rudes zabumbas" (MORAIS FILHO, p. 121 sublinhado meu).

Foi somente em 1878 que a prática do entrudo recebeu proibição severa. No período do Carnaval tipógrafos confeccionavam impressos específicos voltados para a festividade, mas também havia a imprensa conservadora que era contrária à manifestação, e as reclamações dessa imprensa baiana seguiam a denunciar as comemorações nas ruas até 1901 “atacando-o como 'bárbaro' e 'incivilizado', associando-o à cultura festiva afro-baiana" (ICKES, 2013, p. 204).

É curioso o fato de Nina Rodrigues considerar o Carnaval do final da segunda metade do século XIX na Bahia como sendo uma manifestação intermediária das identidades africanas incorporadas. Nina Rodrigues ainda se refere aos negros deste período como "usança africana" remetendo-os genericamente à condição servil praticada por muitos africanos transplantados. $O$ protagonismo negro nas comemorações carnavalescas da Bahia também é indicado por Nina Rodrigues que escreveu: "as festas carnavalescas da Bahia reduzem-se ultimamente quase que a clubes africanos organizados por alguns africanos, negros crioulos e mestiços", e segue sua narrativa ao reconhecer a existência de clubes importantes, "os clubes mais

\footnotetext{
${ }_{9}^{9}$ Para mais, pesquisar: (ICKES, 2013; VIANNA, 1965, p. 285; BUTLER, 1998a; BUTLER, 1998b).
} 
ricos e importantes têm sido A Embaixada Africana e os Pândegos da África" (RODRIGUES, 2008, p. 169).

Para falar sobre os clubes carnavalescos africanos no Carnaval de Rua de Salvador, Nina Rodrigues utilizou-se de fontes da imprensa local que davam detalhes sobre o cortejo, e também, parece ter usado da sua observação pessoal da festividade, assim como fez em seu ensaio $O$ animismo fetichista, estudo antropológico com metodologia empírica e analítica sobre as manifestações religiosas dos africanos, negros crioulos e mestiços na Bahia. ${ }^{10}$ Apesar de reconhecer e citar os dois clubes importantes e ricos do Carnaval da Bahia no ano de 1989, Nina Rodrigues citou também aqueles que ele considerou menores, tais como A Chegada Africana e os Filhos da África. Segundo seu ensaio havia muitos clubes anônimos, além dos "máscaras negras isolados" (RODRIGUES, 2008, p. 169).

O ensaio de Nina Rodrigues auxilia na interpretação sobre os ornamentos utilizados por esses clubes e que foram citados no editorial crítico d'A Coisa pelo seu editor Jayme Borreaux. No ano de 1899, o clube Embaixada Africana, formado por um grupo de negros que Nina Rodrigues chamou de "melhor adaptados", na tentativa de exaltar certo grau de inteligência, celebrou em seus motivos e fantasias o mundo do Egito e da Etiópia, considerados pelo autor como "os povos cultos da África” (RODRIGUES, 2008, p. 170). Aos outros clubes, cujas escolhas foram celebrar outros países e regiões do continente africano, Nina Rodrigues os considerou menos inteligentes e "totêmicos", uma maneira de generalizar uma experiência humana dando a elas concepção mais pragmática desprovida de raciocínio elaborado. O autor citou a descrição de um jornal sobre o desfile do clube Pândegos da África:

(...) representa a margem do Zambeze, em cuja riba, reclinado em imensa concha, descansa o rei Labossi, cercado dos seus ministros Auá, Oman, Abato, empunhando o último estandarte do clube. Após vinha um carro com dois sócios representando poderosos influentes

\footnotetext{
${ }^{10}$ Para mais, ver: (RODRIGUES, 2005). 
da corte do rei, Barborim e Rodá. Três cavaleiros precediam a charanga africana que vinha a pé, com os seus instrumentos estridentes e impossíveis. Depois, um carro representando a cabana do pai Ajou e sua mulher com o caboré de feitiço, a dar a boa sorte a tudo e a todos". ${ }^{11} \mathrm{O}$ sucesso desse clube foi enorme. Vimos compacta multidão de negros e mestiços que a ele, podemos dizer, haviam se incorporado e que o acompanhavam cantando as cantigas africanas, sapateando as suas danças e vitoriando os seus ídolos ou santos que lhes eram mostrados do carro do feitiço. Dir-se-ia um candomblé colossal a perambular pelas ruas da cidade. E, de fato, os negros fetichistas vingavam-se assim das impertinências intermitentes da polícia, exibindo em público a sua festa (RODRIGUES, 2008, p. 170).

Percebe-se a partir da citação de Nina Rodrigues que a população negra da década de 1899 parecia ser consciente da sua identidade e raiz africana. E sua memória afetiva do continente africano se materializava a partir das homenagens e dos motivos escolhidos para representar a sua casa, a África, nos desfiles dos seus clubes carnavalescos. A consciência da sua identidade e dos seus limites cerceados fica evidenciada quando o autor se refere a opressão policial sempre pronta para controlar as manifestações culturais e religiosas características dos africanos no culto às suas ancestralidades. Nesse caso, as medidas opressoras pareciam não ter validade durante os desfiles do Carnaval, e, por essa razão, Nina Rodrigues acreditou que os foliões africanos, negros crioulos, mulatos e mestiços se sentissem vingados ao longo da festa. Não obstante, ao voltarmos às considerações do editorial de Jayme Borreaux, suas críticas e narrativa interessa-nos não somente para a percepção dos costumes e do cotidiano dos povos de descendência africanas no Brasil de 1898, mas, também, para tentar entender a ordem de pensamento dos redatores d'A Coisa na produção de sentidos.

\footnotetext{
${ }^{11}$ Diário da Bahia, 16 de fevereiro de 1899. Nina Rodrigues cita a fonte de onde havia saído a crítica sobre o desfile, mas utiliza-se da citação dando a entender que apenas o seu depoimento poderia não bastar para os céticos.
}

Caderno Pesquisa do Cdhis | Uberlândia, MG | v.32 | n.1 | jan./jun.. 2019 | ISSN 1981-3090 
Os clubes africanos foram importantes para o seu período. Manuel Querino deu nota dos desfiles desses mesmos clubes citados em seu ensaio. O autor fez um comparativo da prática carnavalesca da Bahia com algumas regiões de África. Usou como fonte complementar da sua observação as críticas do Jornal de Notícias do dia 15 de fevereiro de 1899. No entanto, as observações pessoais de Manuel Querino parecem agradá-lo mais. Em sua narrativa do Carnaval em Salvador, Manuel Querino auxilia com um dado hipotético ao considerar o termo Ojou ligado ao universo africano "o prestígio dos Pandegos fechava com um carro representando a tenda de Pae-Ojôu; o da Embaixada, com uma critica" (QUERINO, 1938, p. 104). Manuel Raymundo Querino oferece uma parte do seu ensaio para narrar os dias do Carnaval, onde os clubes africanos protagonizavam a cena. Devido a riqueza dos detalhes de sua escrita, considero importante constar a íntegra de suas considerações, privilegiando o olhar de um autor negro sobre um Carnaval protagonizado por negros:

Em 1897, fôra aqui realizado o carnaval africano com exhibição do Club Pandegos d'Africa, que levou a effeito a reproducção exata do que se observa em Lagos. O prestito fora assim organizado: na frente iam dois príncipes bem trajados; após estes, a guarda de honra, uniformizada em estylo mouro. Seguia-se o carro conduzindo o rei, ladeado por duas raparigas virgens e duas estatuêtas allegoricas. Logo depois via-se o advinhador á frente da charanga, composta de todos os instrumentos usados pelo feiticismo; sendo que os tocadores, uniformizados á moda indigna, usavam grande avental sobre calção curto. $\mathrm{O}$ acompanhamento era enorme; as africanas, principalmente, tomadas de verdadeiro enthusiasmo, cantavam, dansavam e tocavam durante todo o trajecto, numa alegria indescriptivel. Acerca dessa festa o Jornal de Notícias, de 15 de Fevereiro de 1899, assim se externou: “Os clubs vistosamente se apresentaram recolhendo applausos e saudações dos seus adeptos numerosos. Foram elles: A Embaixada Africana e os Pandegos de Africa, já apreciados do nosso publico, por quanto desde uns três annos disputaram-se a palma nessas festas, cuja animação é de justiça dizer, muito lhes deve, pelo capricho com que as sustentam, ambos, hontem, percorreram luzidos e bem dispostos um longo itinerário em que receberam, por vezes, ruidosas ovações, sendo 
grande o acompanhamento de povo que lhes dava guarda de honra. “O Estandarte da Embaixada era empunhado pelo rei Ptolomeu - Pharaó sobre um grande elephante; e o dos Pandegos de Africa, pelo rei Lobossi á sombra de uma enorme concha, cada um delles tendo pagem aos lados e acompanhados de guarda de honra". Foram dois carros bonitos, bem preparados. O prestito dos Pandegos fechava com um carro representando a tenda de Pae-Ojôu; o da Embaixada, com uma critica (aspas do autor QUERINO, 1938, p. 103-104).

Esses mesmos clubes formados por negros são citados em um capítulo de livro organizado por João José Reis, em 1988, no qual os clubes africanos são vistos pelo antropólogo inglês Peter Fry como clubes secundários que foram incorporandose ao Carnaval da elite baiana que mantinha os clubes Fantoches da Euterpe, Cruz Vermelha e Inocentes em Progresso. Segundo as considerações de Peter Fry os clubes Pândegos d'África e Chegada Africana estiveram em atividade de 1895 até 1897, e o clube Guerreiro d'África teria surgido em 1892 e durado até 1895, e se tratavam de "grandes clubes negros, que, como nos dias do entrudo, também entraram na brincadeira, porém não mais como escravos, mas como homens livres ou que experimentaram limites de uma liberdade concedida pelos senhores". E, segue ele, esse "apogeu" dos clubes carnavalescos negros se deveu em razão de os clubes carnavalescos formados pela elite tida como branca, se manter nos desfiles sem regularidade (FRY, 1988, p. 250).

A historiadora Wlamyra Albuquerque destacou a queda do número de africanos na Bahia na segunda metade do século XIX, e faz compreender que mesmo aqueles trazidos bem jovens para o Brasil enfrentavam entraves que cerceavam o seu reconhecimento enquanto cidadão brasileiro, mesmo no período da República, cuja sociedade estava hierarquicamente sistematizada (ALBUQUERQUE, 2009, p. 196). Todavia existia a presença africana no Brasil, especialmente na Bahia, assim como o trânsito comercial de alguns africanos que tentavam explorar a atividade comercial no Brasil republicano. Entendo a partir de Wlamyra Albuquerque que a prática do 
Carnaval para muitos negros era uma maneira deles manterem alguns signos e vínculos com a terra mãe, a África (ALBUQUERQUE, 2009, p. 195).

\section{Ajahi, Ojous e a estereotipia: o forjamento de uma identidade africana}

Em 27 de fevereiro de 1898 os editores publicaram na capa da edição especial de Carnaval d'A Coisa, telegrama que sugere postagem de Moçambique, é um novo leitor que faz alusão ao continente africano. O telegrama é assim escrito: "Moçambique, 23. - Redacção di Cossa. - Bahia - Corre aqui. Sahiu Cranabá ahi Crub «Pandigo di Africa», mai porém qui roupa di elle é ai Asia. - Ajahi". ${ }^{12}$ Ajahi é uma personagem caracterizada enquanto um africano boçal através do seu modo de escrever, muito demarcado pela oralidade e a coloquialidade da sua época. Ahaji é a representação de uma possível experiência negra, de um sujeito inserido na cultura que, alheia a sua fragmentou o seu modo de pensar e existir, mas que, a partir da possibilidade de expressar alegria e o saudosismo a sua terra, se colocou ativo nas páginas de um impresso. Albuquerque nos diz que os desfiles do Carnaval são "textos inteligíveis e legitimados por aqueles que estavam nas margens" (ALBUQUERQUE, 2009, p. 197).

Ajahi reaparece pouco depois com novo telegrama publicado n' A Coisa do dia 4 de setembro de 1898. O título faz entender que o telegrama havia sido emitido da África no dia 30, e se inicia da seguinte maneira: “Sió M. Leite. - N’A Coisa. Bahia. Nosso tudo tá munto contente cum A Cossa, qui fai um ano hoje. Parabem, in nome di anani tudo. - Ajahi". ${ }^{13}$ Esses Ajahis e Ojous são representações capazes de constituir uma ideia de sujeito, aquele que atua, pressiona, confere sentido ao mundo que vive a partir de práticas. Desse modo, tanto o discurso quanto a possibilidade real de uma experiência vivida por africanos na Bahia, constituem representações, construções de um grupo em determinado contexto histórico, atravessado por

\footnotetext{
${ }^{12}$ A Coisa, 27 fev. 1898, ano 1, n. 27, p. capa

${ }^{13}$ A Coisa, 4 set. 1898 , ano 2, n. 54, p. 2 
múltiplas práticas, impossíveis de terem seus códigos integralmente ou totalmente decifrados. ${ }^{14}$

Ojou de fevereiro de 1897 poderia ser o mesmo de 1898 se o autor do telegrama usou da ironia e do chiste para a representação de um africano infantilizado, analfabeto, incapaz de assimilar uma cultura que não seja a sua, um crioulo ou petit-nègre. Mas, ao se comparar a carta-resposta de Ojou ao editor-chefe Jayme Borreaux com a mensagem dos telegramas parece que a distância entre esses dois/três Ojous apenas aumenta, principalmente se considerar a tentativa do segundo de não permitir que o leitor d'A Coisa seja convencido por Jayme Borreaux de que todos os africanos sejam boçais, vis, somíticos, avarentos, anti-higiênicos, trigueiros, sujos, inúteis e engraçados. Na hipótese de que seja, o Ojou da carta-resposta que abre esse texto, um negro de descendência africana consciente do seu lugar étnico, da sua cultura, inteligência, consciência histórica da escravização e resistência de povos africanos; caso se trate da mesma pessoa, por que Ojou permitiria a publicação de mensagens que traduziriam um pensamento comum degradante e chistoso sobre os negros?

Na edição do dia primeiro de janeiro de 1898, há novo aparecimento de um telegrama com o intertítulo Africa (sic), 29, novamente assinado por Ojou. A mensagem em companhia de outras narra sobre a recepção d'A Coisa.$^{15}$ Interessa o reaparecimento de Ojou com mais uma referência ao continente da África. No pequeno texto, as referências africanas são evidentes desde o seu intertítulo e seguem até o corpo da mensagem com a utilização de uma ortografia coloquial ou certo

\footnotetext{
${ }^{14}$ Para mais, ver: (CHARTIER, 1990).

${ }^{15}$ A Coisa, 1 de janeiro de 1898, ano I, n. 19., p. 4, Telegrammas. " «MOCOTÓ SEM SAL, 26 - Redacção $\mathrm{d}^{\prime}$ «A Coisa». -Povo aqui muito satisfeito por ter tido «Coisa» grande. Saudações. - Dondana». «CIDADE SANHAÇOS, 27. - Redacção $\mathrm{d}^{\prime}$ «A Coisa». - Saudações. População alegre tamanho $\mathrm{d}^{\prime}$ «A Coisa». Moças e velhas satisfeitas. - K. J.» «PAPA-SIRIS, 28. - Redacção d' «A Coisa». - Reina muita alegria por estar «A Coisa» mais bonita, maior. Saudações. - K. Mondongo.»".
} 
estrangeirismo: “"AFRICA, 29. - Redacção di «Coisa». - Nosso tudo fico alegre quando recebeu «Coisa» mai grande. - Ojou.»". ${ }^{16}$

A mensagem diz respeito ao fato de um grupo de pessoas alegres ao receberem uma correspondência maior. $O$ texto também faz remeter ao terceiro número do jornal, de 12 de setembro de 1897, no qual são veiculadas as mensagens de Nana de Paris, e John de Londres. ${ }^{17}$ A grafia da mensagem de Ojou se aproxima do estrangeirismo de John, embora reservem pequenas diferenças semânticas.

Aprendi com Achille Mbembe que existe um viés interpretativo a partir da leitura e da escrita de um texto que nos remete ao conceito de consciência ocidental do Negro, ou seja, um texto primeiro, produzido, repetido e consolidado pelo colonizador que se encarregou de inventar o Negro (MBEMBE, 2014). Na literatura o texto primeiro corresponde ao que Irele nomeia de literatura do exotismo, com indicação da inserção da África e das africanidades como o oposto da Europa. Segundo Irele a África foi criada no Ocidente para ser o local da negação (IRELE, 2001).

A esse texto primeiro, afirma Mbembe, responde um texto segundo, simultaneamente gesto de autodeterminação, modo de presença em si, olhar interior e utopia crítica (MBEMBE, 2014, p. 58), que se constitui a partir de outra categoria de interrogações feitas na primeira pessoa do singular "Quem sou eu - serei isso que eles dizem de mim? Será verdade que não sou nada a não ser isto? " (MBEMBE, 2014, p. 58).

Mbembe postula que

se a consciência ocidental do Negro é um julgamento de identidade, o texto segundo será (...) uma declaração de identidade, por meio da qual o Negro diz de si mesmo que é aquilo que não foi apreendido, aquele que não

\footnotetext{
${ }^{16}$ A Coisa, 1 de jan.1898, ano I, n. 19, p. 4

${ }^{17}$ Telegramas de Nana de Paris seguido por John de Londres: “J'ai beaucoup aimé votre Chose. Elle n'a qu'un seul défaut: c'est d'étre trop petite"; "Mi recebeu Coisa. Mi mulher diz não serve, mui pequena", ver: A Coisa, 12 de set. 1897, ano I, n. 3, capa
} 
está onde se diz estar, e muito menos onde o procuramos, mas antes no lugar onde não é pensado (MBEMBE, 2014, p. 59).

Assim, ao refletir acerca da identidade negra incorro na questão dos discursos históricos, especialmente quando lanço o olhar sobre a ideia do Negro na literatura seja essa difundida em livros ou impressos, que envolve a construção de sujeitos múltiplos e identidades variadas. O sujeito e suas identidades parecem se estabelecer sobre uma paradoxal duplicidade a identidade determinada e o conhecido consciente, mas igualmente o indeterminado.

A historiografia em torno da construção de uma imagem do negro a ser investigada por meio da literatura ou da imprensa indica a análise, verificação, descrição, construção e reconstrução de discursos sobre a crítica interna e externa de documentos que valorizam sua "intencionalidade inconsciente" se é que não devo referir a essa intenção enquanto consciente.

Os redatores d'A Coisa ao intitularem o primeiro telegrama de Ojou com a referência da região que compreendia uma grande concentração de povos do grupo étnico-linguístico banto, suaílis e árabe, o autor da mensagem ou o redator final responsável pela inserção do título Moçambique, comete o equívoco de assiná-la com um nome que remete a um grupo étnico-linguístico iorubá, podendo inclusive ter incorrido ao equívoco linguístico da grafia de origem africana da palavra Ojú. Ao pesquisar nos dicionários Árabe, Iorubá e Guarani, encontrei a palavra Ojou apenas no dialeto indígena Guarani. A definição e significações encontradas foram as seguintes: -jou: verbo transitivo direto: 1 . Achar; 2. Obter, sendo Ojou ${ }^{18}$ - ele achou/ela acha. ${ }^{19}$ Assim, Ojou seria o equivalente na língua portuguesa de um pronome, e desse modo é de se estranhar a denominação de Ojou para designação de um nome

\footnotetext{
${ }^{18}$ Ojou xekuã régua: ele achou meu anel; o- jou xe-kuã régua, $3^{\mathrm{a}} \mathrm{p}$. sing. Achar meu anel. Na língua Guarani não há tempo verbal que se conjugue. Todas as ações se manifestam no equivalente ao verbo do português no infinitivo

${ }^{19}$ Colaboração da pesquisadora Ivana Pereira Ivo, linguista especializada em fonética e fonologia do GuaraniMbyá.
} 
próprio, principalmente considerando a temporalidade em questão, período em que as delimitações culturais de língua demarcavam hierarquias, saberes, lugares e nãolugares para negros, índios, brancos, pardos e crioulos, ${ }^{20}$ e estrangeiros.

No período de circulação do jornal o sistema ortográfico se configurava de outra maneira, por isso, se levanta a hipótese de Ojou se referir a uma variação da palavra de origem africana Ojú, embora escrita por um brasileiro, a seu modo, como ele entendia ser, ou até mesmo se tratar de uma coincidência que a aproxime com a palavra Guarani, o que não era impossível para a época, pois a língua geral de base Tupi era muito falada, especialmente em Salvador. O dicionário Iorubá traz a palavra Ojú, que poderia ser atribuída a um nome próprio por se tratar do equivalente a um substantivo na língua portuguesa, que em sua tradução para o português seria Olho.

O domínio da sintaxe e ortografia, a consciência política e o discurso racial narrados na carta-resposta de Ojou, não podem ser tomados como uma representação meramente ficcional, mas especialmente como uma representação clivada do cotidiano da época que resguardava personagens negros intelectuais como Manuel Raymundo Querino, alfabetizado e etnógrafo das artes e da tipografia que viveu na época de produção e circulação d'A Coisa. Entendo a partir de Roger Chartier, que todo documento é representação do real que se apreende e não se pode desligar de sua realidade construída, pautada em suas próprias regras e códigos. Esses códigos e regras estabelecem um universo de historicidade de sua produção e intencionalidade da sua escrita. Assim, todo tipo de texto/imagem possui uma linguagem específica, na qual foi produzido, instituindo uma ideia de dada realidade (CHARTIER, 1990, p. 62-63).

Na carta-resposta de Ojou estão explicitadas tensões raciais em curso opondo Africanos a Europeus ou Negros a Brancos. Percebe-se que em sua tentativa de justificar as qualidades negativas atribuídas aos africanos pelo artigo de Jayme

\footnotetext{
${ }^{20}$ A definição de crioulo se deve ao filho do africano negro que nascia no Brasil. 
Borreaux, o autor Ojou, o faz retribuindo essas negativas aos brancos, os ex-senhores de escravos responsáveis por "não os educar adequadamente". A avareza atribuída aos africanos é para a personagem Ojou, o resultado do comportamento explorador dos brancos, gerando nos negros o desejo pelo acúmulo financeiro para a compra de suas próprias liberdades.

Ao me referir a Achille Mbembe e sua percepção do texto segundo, faz-se necessário ressaltar as distâncias da personagem Ojou em todos os seus aparecimentos. Exceto pelo nome com o qual são identificadas suas mensagens, a personagem sai de um estado grosseiro para modos refinados na linguagem. O texto primeiro, representando a efetividade do seu deslocamento demarca novas identidades, e passa a assumir um mundo, assumindo o instrumento cultural do homem branco que é a apropriação reivindicada de linguagem escrita.

\section{Referências bibliográficas}

ALBUQUERQUE, W. R. O jogo da dissimulação: abolição e cidadania negra no Brasil. São Paulo: Companhia das Letras, 2009.

APPLEGATE, E. Muckrakers: a biographical dictionary of writers and editors. Maryland: Scarecrow Press, 2008.

BASTIDE, R. Estudos afro-brasileiros. São Paulo: Perspectiva, 1983.

BUTLER, K. Freedoms Given, Freedoms Won: Afro-Brazilians in Post-Abolition, São Paulo and Salvador, New Brunswick, N.J.: Rutgers University Press, 1998.

Afterword: Ginga Baiana, the politics of Race, Class, Culture, and Power in Salvador, Bahia, in KRAAY, H. (Org.), Afro-Brazilian Culture and Politics: Bahia, 1790s to 1990s. Londres: ME Sharpe, 1998, pp.158-75.

CHARTIER, R. A História Cultural: entre práticas e representações. São Paulo: Difel, 1990.

CUNHA, S. H. dos P. Um retrato fiel da Bahia: sociedade-racismo-economia na transição para o trabalho livre no Recôncavo açucareiro, 1871-1902, Campinas, 2004. 
Tese. (Doutorado em Ciências Econômicas). Universidade Estadual de Campinas Unicamp. $272 \mathrm{f}$

DEARMENT, R. K. Grunfighter in Gotham: bat masterson's New York City years. Oklahoma: University of Oklahoma Press, 2013.

DOLTO, F. A imagem inconsciente do corpo. São Paulo: Perspectiva, 1992.

FONSECA, A. A. da. Esboço typographico. Salvador: Typographia da Gazeta do Povo, 1909.

FRY, P. Negros e brancos no Carnaval da Velha República, in. REIS, J. J. (Org.). Escravidão e invenção da liberdade. São Paulo: Brasiliense, 1988.

GAMBONE, R. L. The popular Art and illustrations of George Benjamin Luks. University Press of Missisipi, 2009.

GOMES, N. L. Sem perder a raiz: corpo e cabelo como símbolo da identidade. Belo Horizonte, 2006.

GORDON, L. R. Nota de tradução, in: FANON, F. Pele negra, máscaras brancas. Salvador: EDUFBA, 2008.

ICKES, S. Era das batucadas: o carnaval baiano das décadas 1930 e 1940. Afro-Ásia [online]. 2013, n.47, pp. 199-238. Acesso em: 12 dez. 2014.

IRELE, A. African imagination: literature in Africa and the black diaspora. New York: Oxford University Press, 2001.

LEHMKUHL, L.; PEREIRA, T. H. Corpos impressos: técnicas e visualidades na imprensa ilustrada, In. FLORES, M. B. R.; PIAZZA, M. de F. F.; PETERLE, P. (Org.). Arte e pensamento: operações historiográficas. São Paulo: R. Copetti Editor, 2016.

MBEMBE, A. Crítica da razão negra. Lisboa: Antigona, 2014.

MELO, O. A. B. A nacionalidade do Direito Constitucional brasileiro. Revista Estudos Históricos (FGV) - Vol. 15, s/n (1949).

MORAES FILHO, M. Festas e tradições populares do Brasil. Brasília: Senado Federal, Conselho Editorial, 2002.

QUERINO, M. Costumes africanos no Brasil. Prefácio e notas de A. Ramos. Rio de Janeiro: Civilização Brasileira, 1938. 
RODRIGUES, N. R. Os africanos no Brasil. São Paulo: Madras, 2008.

Animismo fetichista dos negros bahianos. Salvador: P 555, 2005. (Col A/C/ Brasil, Teatro XVIII).

TAVARES, L. G. P. Artur Arésio da Fonseca: pioneiro do estudo das Artes Gráficas e da editoração. Anais Intercom, GT 07, Editoração (1995).

VIANNA, H. Do entrudo ao Carnaval na Bahia, Revista Brasileira de Folclore, n. 13 (1965), p. 285. 